
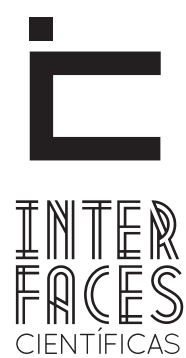

EDUCAÇÃO

\title{
OLHARES DE DOCENTES DE MESTRADOS DA UEFS SOBRE A ARTICULAÇ̃̃O ENSINO-PESQUISA-EXTENSÃO
}

Antonio Roberto Seixas da $\mathrm{Cruz}^{1}$

Murilo Oliveira Almeida ${ }^{3}$

\section{RESUMO}

0 presente artigo tem como objetivo geral compreender os olhares de docentes de mestrados da UEFS sobre a articulação entre o ensino, a pesquisa e a extensão. 0 quadro teórico do estudo amparou-se em princípios da Teoria das Representações Sociais TRS (MOSCOVICI, 1987 e JODELET, 2001) e nos conceitos a seguir: funções da universidade (CUNHA, 2007; PÉREZ GÓMEZ, 2001; ZABALZA, 2004) e qualidade do ensino superior (DOURADO \& OLIVEIRA, 2009; TUBINO, 1997; DEMO, 1995), dentre outros autores. Para alcançar o objetivo proposto, optamos por uma pesquisa descritiva de abordagem qualitativa. Foram sujeitos da pesquisa, cinco docentes dos Programas de Pós-Graduação em História, Cultura e Poder; Desenho, Cultura e Interatividade e Filosofia e História das Ciências que, voluntariamente, aceitaram participar da investigação. Os dados foram coletados e produzidos através de entrevista semi-es- truturada (MARCONI e LAKATOS, 1999; SZIMANSKY, 2004) e tratados com base na técnica da análise de conteúdo de tipo temática, conforme (BARDIN, 1977). Os resultados apontam para o entendimento de que o preparo do docente que atuará na universidade atual, em tempos de complexidade, precisa levar em consideração a importância da indissociabilidade do ensino, da pesquisa e da extensão na prática docente para que os professores, os gestores e a sociedade como um todo possa entender que a universidade nada mais é do que uma instituição criada para ajudar a formar cidadãos conscientes do seu papel social e que tem na pesquisa e na extensão alguns de seus pilares fundamentais.

\section{PALAVRAS-CHAVE}

Ensino. Pesquisa. Extensão. Representações Sociais. 


\section{ABSTRACT}

This article aims to understand the looks of professors of masters of UEFS on the relationship between teaching, research and extension. The theoretical framework of the study has enshrined in the principles of the theory of social representations-TRS (MOSCO$\mathrm{VICl}, 1987$ and JODELET, 2001) and in the following concepts: functions of the University (Cunha, 2007; PÉREZ GÓMEZ, 2001; ZABALZA, 2004) and quality of higher education (Golden \& OLIVEIRA, 2009; TUBINO, 1997; DEMO, 1995), among others authors. To achieve the proposed objective, we chose a descriptive qualitative approach research. Were research subjects, five professors of the graduate programs in History, Culture and Power; Design, Culture and Interactivity and Philosophy and History of Science that, voluntarily agreed to participate in the research. The data were collected and produced through semi-structured interview (MARCONI and LAKATOS, 1999; SZIMANSKY, 2004) and treated based on content analysis technique of thematic type as (BARDIN, 1977). The results point to the understanding that the teacher preparation that will act in the current University, in times of complexity, needs to take into account the importance of the inseparability of teaching, research and extension in teaching practice for teachers, administrators and society as a whole can understand that the University is nothing more than an institution created to help form citizens aware of their social role and that is in the research and to the extension some of its fundamental pillars.

\section{KEYWORDS}

Teaching. Research. Extension. Social Representations.

\section{RESUMEN}

El presente artículo tiene como objetivo general comprender las miradas de los docentes de maestría de la UEFS, respecto a la articulación entre enseñanza, investigación y extensión. El teórico de los estudios se basó en los principios de la Teoría de las Representaciones Sociales - TRS (MOSCOVICI, 1987 y JODELET, 2001) y los siguientes conceptos: funciones de la universidad (CUNHA, 2007; PÉREZ GÓMEZ, 2001; ZABALZA, 2004) y la calidad de la educación superior (DOURADO \& OLIVEIRA, 2009; TUBINO, 1997; DEMO, 1995), entre otros autores. Para lograr el objetivo propuesto, hemos optado por una investigación descriptiva de abordaje cualitativa. Fueron sujetos de la investigación, cinco docentes de los Programas de Postgrado en Historia, Cultura y poder; Diseño, Cultura y Interactividad y Filosofía y Historia de las Ciencias que, voluntariamente aceptaron participar de la investigación. Los datos han sido colectados y producidos a través de entrevista semi-estructurada (MARCONI Y LAKATOS, 1999; SZIMANSKI, 2004) y estudiados con base en la técnica del análisis de contenido del tipo temática, conforme (BARDIN, 1977). Los resultados apuntan a la comprensión de que la preparación para los maestros que actuarán en la universidad de hoy, en tiempos de complejidad, será la de llevar en cuenta la importancia de lo indisociable en la enseñanza, la investigación y la extensión en la práctica docente para que los profesores, los gestores y la sociedad como un todo, puedan entender que la universidad nada más es que una institución creada para ayudar a formar ciudadanos conscientes de su papel social y que posee en la investigación y en la extensión algunos de sus pilares fundamentales.

\section{PALABRAS CLAVE}

Enseñanza. Investigación. Extensión. Representaciones Sociales. 


\section{INTRODUÇ̃̃̃O}

A discussão sobre a indissociabilidade entre ensino, pesquisa e extensão na universidade tem se intensificado nas duas últimas décadas, tornando-se tema de debates de diversos estudiosos da área da educação (CHAUÍ, 2001; PIMENTA, 2005; CUNHA, 2007; RIBEIRO, 2009). Esses autores sinalizam que a prática da investigação na referida instituição colabora para a melhoria da qualidade do seu papel social, se articulada ao ensino e à extensão no seu fazer cotidiano (DEMO, 1997 e 1998).

Investigar sobre essa tríade atualmente constitui-se numa necessidade no campo da pedagogia universitária, pois poderá trazer subsídios para ampliar as reflexões sobre a formação proporcionada pelos cursos de pós-graduação stricto sensu, mestrados da Universidade Estadual de Feira de Santana (UEFS), aos sujeitos que irão atuar ou já atuam no ensino superior.

Nas obras que tivemos acesso, percebemos que as discussões sobre a formação de professores têm enfatizado os aspectos das políticas públicas e das bases legais sobre a profissão docente, olvidando de outros aspectos também importantes para o âmbito universitário. Assim, neste trabalho, buscamos compreender os olhares de docentes de mestrados da UEFS sobre a articulação entre 0 ensino, a pesquisa e a extensão.

\section{MÉTODO}

O estudo baseia-se na Teoria das Representações Sociais (TRS). Segundo Moscovici (1987, p. 28), "os homens tornam inteligível a realidade física e social, inserem-se num grupo ou numa ligação cotidiana de trocas e liberam os poderes de sua imaginação".

Além disso, utilizar-se-á dos seguintes conceitos: funções da universidade (ZABALZA, 1998; PÉREZ GÓMEZ, 2001; CUNHA, 2007); e qualidade do ensino superior (DEMO, 1995; TUBINO, 1997; DOURADO \& OLIVEIRA, 2009).

Investigar fenômenos sociais com base na TRS tem se tornado, segundo especialistas, importante para a análise das questões educacionais, particularmente, da qualidade do ensino superior, o que é de fundamental importância para o entendimento do papel da pesquisa e da extensão na concepção de docentes de mestrados da UEFS (CUNHA, 2007; RIBEIRO, 2009).

Trata-se de uma pesquisa descritiva, de abordagem qualitativa. Os dados da investigação foram coletados

e produzidos através de entrevista semi-estruturada. Para o tratamento desses foi utilizada a análise de conteúdo do tipo temática, conforme Bardin (1977), a qual nos ajudou a compreender as representações dos docentes pesquisadores de cursos de mestrado sobre o objeto em questão.

Os sujeitos da investigação constituiram-se inicialmente de dois docentes pesquisadores de cada um dos cursos de mestrado em História, Cultura e Poder; Desenho, Cultura e Interatividade; e Ensino, Filosofia e História das Ciências, da UEFS, escolhidos a partir daqueles que se dispuseram, voluntariamente, a participar da pesquisa, totalizando seis professores pesquisadores permanentes dos referidos cursos. No entanto, por dificuldades de entrevistar um dos professores do mestrado em Ensino, Filosofia e História das Ciências, os sujeitos da investigação constituiram-se, ao final, em cinco depoentes.

Interfaces Científicas - Educação • Aracaju • V.01 • N.04 • p. 83-91 • out. $2013 \cdot$ www.periodicos.set.edu.br 


\section{RESULTADOSE DISCUSSÃO}

O ensino, a pesquisa e a extensão constituem-se na tríade que caracteriza historicamente a universidade. Por isso, é importante investigar se essa indissociabilidade tem sido alcançada na prática de docentes universitários, pois, segundo diversos autores (DEMO, 1997 e 1998; ANASTASIOU, 1998; CASTANHO, 2000; SOUZA SANTOS, 2004; PIMENTA, 2005), esses elementos ajudam a garantir a qualidade do trabalho na universidade.

Assim, quando indagados a respeito dessa categoria, os cinco entrevistados do estudo revelam suas representações a respeito do objeto em questão. Um dos entrevistados fala sobre a necessidade de um vínculo entre ensino e pesquisa na universidade, pois a investigação é destacada com um dos elementos da essência da profissão docente, como pode ser evidenciado no depoimento a seguir:

Eu vejo um vínculo muito forte entre ensino e pesquisa porque a pesquisa não seria um caráter ou uma qualidade que se possa acrescentar à atividade do docente, ela faz parte da essência de ser docente; não um qualificativo, está na essência: ou você é pesquisador, ou não é docente. Porque exercitar a indagação, buscar o questionamento, tudo isso faz parte da atividade docente, está na raiz da atividade docente. A função do docente é, principalmente, ser pesquisador. Então, eu vejo um vínculo muito grande entre ensino e pesquisa. A extensão eu vejo como uma possibilidade de partilha desses dois vínculos fundamentais: ensino e pesquisa (PARTICIPANTE MW1).

Para o participante MW1, a pesquisa faz parte da vida universitária, ou seja, é um dos aspectos da essência do ser docente em nível superior. Além disso, é necessário que o professor universitário investigue sua prática, pois essa atividade tem como característica a busca, a reflexão, entre outras questões.

Vejamos o que Freire (1998, p. 14) nos diz sobre o professor pesquisador:
Fala-se hoje, com insistência, no docente pesquisador. No meu entender, o que há de pesquisador no docente não é uma qualidade ou uma forma de ser ou de atuar que se acrescente à de ensinar. Faz parte da natureza da prática docente a indagação, a busca e a pesquisa. 0 que se precisa é que, em sua formação permanente, o docente se perceba e se assuma, porque docente, como pesquisador.

Para esse autor, a pesquisa não se trata de uma especialidade ou uma competência a mais que o docente deva ter para exercer bem suas funções, e, sim, uma atividade que faz parte dos elementos que constituem a essência da ação de ensinar, visto que, parte da capacidade de indagação, curiosidade e busca do novo são aspectos que constituem um profissional docente. Esse aspecto da essência do ensinar mostra que a qualidade da universidade atual, em tese, está amparada na tríade ensino, pesquisa e extensão, pois:

\begin{abstract}
[...] Ensino, pesquisa e extensão se constituem em partes importantes, mas intimamente associados no processo pedagógico. A prática da pesquisa me levou a perceber que a transmissão dos conteúdos é precedida pelo ato de produzir o conhecimento e essa produção se faz especialmente pelo ato de pesquisa. [...] Me parece que ensino, pesquisa e extensão tem se tornado cada vez mais elementos indissociáveis na prática de alguém que entende o papel que ele cumpre como um educador, sobretudo no nível superior. [...] Ou seja, ensinar através da pesquisa requer uma difusão mais abrangente do conhecimento, com práticas de extensão (PARTICIPANTE MR5).
\end{abstract}

Segundo o depoente, o ensino, a pesquisa e a extensão são elementos indissociáveis na prática docente universitária (CASTANHO, 2000), e são partes integrantes do processo pedagógico no nível superior. Outro elemento aludido pelo depoente se refere à indissociabilidade entre o ensino e a pesquisa, pois ensinar exige investigação e reflexão para se conhecer o já produzido, a fim de possibilitar a sua socialização. Essa perspectiva da fala revela que existe relação en- 
tre o ser pesquisador e o ser professor, porque não há como exercer uma docência com qualidade sem desenvolver pesquisas sobre temas relacionados à área de interesse do docente, ou seja, faz parte da natureza do trabalho pedagógico a capacidade investigativa, o que está de acordo com o pensamento de alguns autores discutidos neste trabalho.

Vale ressaltar que o depoimento não caracteriza em que consiste a extensão universitária, apenas que esta seria o momento de estender os resultados das pesquisas à comunidade, e que o ensino significa transmitir os conteúdos produzidos pelas investigações acadêmicas realizadas pelos docentes, o que possibilita dizer que a fala sugere uma ideia de educação e de universidade amparada em aspectos do paradigma positivista, no qual o professor é considerado o detentor do conhecimento e o aluno mero receptáculo. Isto se evidencia quando o depoente faz referência à docência como "transferência de conteúdos". Ressaltamos, no entanto, que o excerto anterior traz elementos contraditórios, ora do modelo de prática docente tradicional, ora do modelo de prática emergente.

A concepção da indissociabilidade entre ensino, pesquisa e extensão constitui-se em um dos aspectos que caracterizam uma instituição como universidade. Para um dos sujeitos entrevistados,

[...] 0 ensino, a pesquisa e a extensão é o tripé que sustenta qualquer instituição de ensino superior. Não existe o ensino superior sem a correlação entre esses três elementos de formação do cidadão. 0 ensino é o reflexo daquilo que a sociedade precisa para poder avançar; para você ter um ensino é preciso que você tenha uma pesquisa que você aplique em sala de aula para você não ficar apenas naquele ensino que o livro diz e na transmissão do conhecimento e, sim, na reflexão e na produção de novos conhecimentos; e a extensão é o meio que a gente tem de aproximar a comunidade das nossas pesquisas [...] (PARTICIPANTE MG3).

Segundo o depoente, o tripé ensino-pesquisa-extensão, de maneira indissociada, é imprescindível na prática das universidades brasileiras atuais para a busca da qualidade. Assim, o ensino é o que a sociedade precisa para se desenvolver. Já a pesquisa é o elemento alimentador do ensino e da produção de novos conhecimentos para a academia e para a sociedade. A extensão, então, é a possibilidade de aproximação entre a universidade e a sociedade, a contribuição que a primeira deve à segunda.

Ainda nesse depoimento, percebe-se uma reflexão que revela um certo equívoco, pois, o depoente assinala que "qualquer instituição" tem um compromisso com o tripé ensino-pesquisa-extensão, ao contrário, a formação ofertada pela faculdade visa a preparação para o mercado de trabalho, o que tem sido rediscutido atualmente, inclusive pelos órgãos que avaliam tais organizações, tanto internos quanto externos, como a Coordenação de Aperfeiçoamento de Pessoal do Ensino Superior (Capes), entre outras.

Segundo Souza Santos (2004, p. 46-47),

[...] Só há universidade quando há formação graduada e pós-graduada, pesquisa e extensão. Sem qualquer destes, há ensino superior, não há universidade. Isto significa que, em muitos países, a esmagadora maioria das universidades privadas e mesmo parte das universidades públicas não são universidades porque thes falta a pesquisa ou a pós-graduação.

Diante do excerto, a indissociabilidade entre esses elementos constituem uma universidade, mais ainda, é sua função primordial, entre outras, desenvolver eficazmente a graduação, a pós-graduação e a extensão, em articulação umas com as outras, o que para Souza Santos (2004) não tem acontecido em todas instituições que se denominam de universidade.

Por conseguinte, a graduação, a pós-graduação e as práticas extensionistas são necessidades atuais da universidade, pois:

[...] É obrigatório no mundo universitário brasileiro essa indissociação entre ensino, pesquisa e extensão. [...] A pesquisa é como um 'bumerangue' entre o do-

Interfaces Científicas - Educação • Aracaju • V.01 • N.04 • p. 83-91 • out. $2013 \cdot$ www.periodicos.set.edu.br 
cente que pesquisa e que forma alunos pesquisadores ou que traz sua pesquisa para ser discutida e trabalhada em sala de aula com seu aluno. [...] A extensão faz parte de uma pesquisa, não prescinde da pesquisa, é um tipo de pesquisa que tem uma preocupação maior com o retorno, não apenas para dentro da universidade, mas para fora. [...] Eu acho que são três momentos distintos dentro do conhecimento universitário que eu pessoalmente não sei se eu consegui articular os três (PARTICIPANTE MI2).

A universidade, no depoimento, constitui-se na tríade já anunciada. Percebe-se, também, que a pesquisa é uma das funções da universidade e tem relação intrínseca com o ensino e a extensão, pois a produção do conhecimento da humanidade é, antes de tudo, resultante de um processo científico de investigação dos sujeitos historicamente situados e que contribui para a aprendizagem dos estudantes na sala de aula universitária.

Outra questão sinalizada pelo entrevistado é que existem responsabilidades no trabalho com a pesquisa institucional, como por exemplo, a financeira, de pessoal de trabalho, material. A extensão, para esse sujeito da investigação, constitui-se num retorno dos resultados das pesquisas realizadas no seio acadêmico para a própria comunidade universitária e extra-universitária e, também, é um processo eminentemente formativo. Assim, a extensão denota o resultado de um trabalho de pesquisa comprometido com o retorno para a sociedade.

Dessa maneira, o entrevistado elege algumas características da extensão: é formativa; visa o retorno à comunidade; tem um alcance social; não é fácil de realizar porque exige demandas de pessoal, responsabilidade financeira e material, dentre outras questões que envolvem o processo. Ao final de sua exposição, o entrevistado admite que não sabe se consegue efetivar a tríade ensino, pesquisa e extensão.

Sobre a extensão universitária, segundo Saviani (1985, p. 48),
A terceira função, que é a de extensão, significaria a articulação da universidade com a sociedade, de tal modo que aquilo que ela produz em termos de novos conhecimentos e aquilo que ela difunde através do ensino não ficassem restritos apenas àqueles elementos que conseguem ser aprovados no vestibular e que integram determinado curso objetivando se formar numa determinada profissão. Ao contrário, cabe à universidade socializar seus conhecimentos, difundindo-os à comunidade e se convertendo, assim, numa força viva capaz de elevar o nível cultural geral da sociedade.

Em decorrência da citação, o ensino, a pesquisa e a extensão são aspectos que devem, portanto, estar imbricados na prática educativa dos docentes do ensino superior, sendo que os professores universitários necessitam se atualizar sobre o seu campo de saber específico para poder cumprir o seu papel social.

Quando indagado a respeito da sua concepção sobre ensino, pesquisa e extensão, outro docente afirma o seguinte:

Como docente universitário eu uno esses três eixos: 0 ensino, a pesquisa e a extensão. 0 de ensino seria o ato de ensinar aquilo que foi produzido pela pesquisa. Então, aqui na universidade a gente ensina, produz conhecimento e aí pelo fato de produzir conhecimento através da pesquisa e, também, daquilo que é difundido na extensão a gente acaba ensinando os resultados daquilo que foi produzido historicamente. Então eu definiria o ensino dessa maneira: o ato de ensinar, o ato de difundir a produção tanto da pesquisa quanto da extensão (PARTICIPANTE MM4).

A fala anterior indica que há necessidade de uma articulação entre esses três eixos básicos (ensino-pesquisa-extensão) na prática educativa. 0 ensino caracteriza-se como a socialização da pesquisa. Esta é responsável pela produção de novos conhecimentos, e a extensão tem como meta a difusão da investigação na universidade e fora dela. No entanto, o depoente defende a concepção de ensino centrada no professor como transmissor de conteúdos das pesquisas e da extensão que denota características do modelo de ensino conservador, e não discute o que seria de fato uma prática extensionista na universidade atual. 
Nesse sentido, para Tubino (1997, p. 5), “a universidade contemporânea, nas suas inúmeras complexidades, apresenta-se com uma grande missão, que é justamente a busca permanente da unidade ensino-pesquisa-extensão-cultura”. Na busca de meios para desenvolver esse tripé, tem-se exigido do professor universitário uma docência com mais qualidade, aquela que tenha na pesquisa um de seus pilares fundamentais.

\section{CONCLUSÃO}

Com o objetivo de compreender os olhares de docentes de mestrados da Universidade Estadual de Feira de Santana (UEFS) sobre a articulação entre o ensino, a pesquisa e a extensão em suas práticas pedagógicas, realizamos este estudo de abordagem qualitativa.

O intuito foi o de contribuir para aclarar as discussões referentes à questão da qualidade do ensino superior, enfatizando o papel do docente universitário nos tempos atuais, procurando-se saber sobre as influências da pesquisa em articulação com o ensino e a extensão, em suas práticas pedagógicas no contexto da sala de aula.

Percebeu-se como um elemento comum às falas dos depoentes que o ensino, a pesquisa e a extensão são elementos indissociáveis na prática docente universitária e integram o processo pedagógico na universidade. Essa relação ensino e pesquisa na sala de aula universitária existe porque para ensinar é necessário pesquisar. Há, por consequência, relação entre pesquisador e bom docente porque, segundo alguns entrevistados, não há como exercer uma docência com qualidade sem desenvolver pesquisas sobre temas relacionados à área de interesse do professor.

$\mathrm{Na}$ análise dos dados revelou-se, ainda, que a pesquisa faz parte da vida universitária, ou seja, é um dos aspectos da essência do ser docente em nível superior. Além disso, o professor necessita ser um sujeito que investiga sua prática, pois a atividade docente tem como características a busca, a reflexão, entre outras questões. Nesse sentido, alguns dos entrevistados consideram que o docente universitário deve ser um pesquisador.

Outra questão sinalizada por alguns dos entrevistados de nossa investigação é que existe uma responsabilidade no trabalho com a pesquisa institucional. São elas: financeira, de pessoal de trabalho, material, entre outras. A extensão, para alguns sujeitos da investigação, constitui-se num retorno dos resultados das pesquisas realizadas no meio acadêmico para a própria comunidade universitária e extra-universitária e, também, é um processo eminentemente formativo. Assim, a extensão denota o resultado de um trabalho de pesquisa comprometido com o retorno para a sociedade.

Segundo alguns depoimentos, o ensino foi identificado como o elemento que tem como meta abordar as questões que a sociedade precisa para se desenvolver. Já a pesquisa é o elemento que alimenta esse ensino e visa à produção de novos conhecimentos para a academia e para a sociedade. A extensão, então, é a possibilidade de aproximação entre a universidade e a sociedade, oportuniza a socialização de saberes que são elaborados na academia.

Consideramos, portanto, que alguns dos depoentes discursaram sobre o que seria o ensino, a pesquisa e a extensão, bem como a sua indissociabilidade, mas não conseguiram afirmar que vivenciam esse tripé ligado às funções da universidade nas suas práticas de sala de aula no âmbito dos mestrados da UEFS. 


\section{REFERÊNCIAS}

ABRIC, Jean-Claude. L'organisation interne des representations sociales: système central et système périphérique. In: GUIMELLI, C. (Éd.) Structures et transformation de Représentationes Sociales. Neuchâtel: Delachaux et Neestlé. p. 73 -84, 1994 b.

ANASTASIOU, Léa das Graças Camargos. Metodologia do ensino superior: da prática docente a uma possível teoria pedagógica. Curitiba: IBPEX, Autores Associados, 1998.

ARROYO, Miguel G. Ofício de mestre: imagens e autoimagens. 11 ed. Petrópolis, RJ: Vozes, 2009.

BARDIN, L. L'analyse de contenu. Paris: Presses Universitaires de la France, 1977.

CASTANHO, Sérgio. A universidade entre o sim, o não e o talvez. In: VEIGA, Ilma Passos de Alencastro. Pedagogia universitária: a aula em foco. Campinas, SP: Papirus, 2000.

CHAUÍ, Marilena de Souza. Escritos sobre a universidade. São Paulo, SP: Ed. UNESP, 2001.

CUNHA, Maria Isabel (org.). Reflexões e práticas em pedagogia universitária. Campinas, SP: Papirus, 2007.

DEMO, Pedro. Educação e qualidade. 2. ed. Campinas, São Paulo: Papirus, 1995.

DEMO, Pedro. Educar pela pesquisa. 3. ed. Campinas, São Paulo: Autores Associados, 1998.

DEMO, Pedro. Pesquisa: principio científico e educativo. 5 ed. São Paulo: Cortez, 1998.

FREIRE, Paulo. Pedagogia da autonomia: Saberes necessários à prática educativa. 8 ed. São Paulo: Editora Paz e Terra, 1998.

GATTI, Bernadete (org.). Identidade profissional docente: um referencial para a pesquisa. Revista Educação e Linguagem. Programa de Pós-Graduação em Educação: Universidade Metodista de São Paulo. Vol. 1, $\mathrm{n}^{0} 1$, 1998.

JODELET, Denise. Representações sociais: um domínio em expansão. In: (org.). As representações sociais. Tradução: Lilian Ulup: Rio de Janeiro: Editora da UERJ, 2001.

MOSCOVICI, Serge. A representação social da psicanálise. Rio de Janeiro: Zahar, 1987.

PIMENTA, Selma Garrido. Docência no ensino superior. 2. ed. São Paulo: Cortez, 2005.

RIBEIRO, Marinalva Lopes. A prática educativa de professores: representações de estudantes no contexto da formação. In: CUNHA, Maria Isabel; SOARES, Sandra Regina; RIBEIRO, Marinalva Lopes (Orgs.). Docência universitária: profissionalização e práticas educativas. Feira de Santana, BA: UEFS Editora, 2009. 
SANTOS, Boaventura de Sousa. A universidade no século XXI: para uma reforma democrática e emancipatória da universidade. 2. ed. São Paulo, SP: Cortez, 2004.

SAVIANI, Dermeval. A universidade e o ensino. In: Ensino público e algumas falas sobre universidade. São Paulo: Cortez Autores Associados, 1985.

VEIGA, Ilma Passos Alencastro. Docência como atividade profissional. In: VEIGA, Ilma Passos Alencastro; D`ÁVILA, Cristina Maria (Orgs.). Profissão docente: novos sentidos, novas perspectivas. Campinas, SP: Papirus, 2008.

ZABALA, Antoni. A prática educativa: como ensinar. Porto Alegre: Artmed, 1998.

1 Professor titular do Departamento de Educação da Universidade Estadual de Feira de Santana (UEFS). Coordenador do Núcleo de História da Educação na Bahia (Nuheb) e pesquisador do Núcleo de Estudos e Pesquisas sobre Pedagogia Universitária (Neppu/UEFS). Email: seixasecruz@uol.com.br

2 Pedagogo, especialista em Metodologia e Didática do Ensino Superior pelo Núcleo de Pós-Graduação Gastão Guimarães, estudante do Mestrado em Educação, da UEFS, vinculado ao Neppu, e bolsista da Fundação de Amparo à Pesquisa do Estado da Bahia (Fapesb). Email: murilooliveiraalmeida@yahoo.com.br 